\title{
Growth Hormone Treatment of Short Stature: Status of the Quality of Life Rationale
}

\author{
David E. Sandberg Melissa Colsman \\ Departments of Psychiatry and Pediatrics, School of Medicine and Biomedical Sciences, University at Buffalo, \\ State University of New York, Buffalo, N.Y., USA
}

\section{Key Words}

Short stature $\cdot$ Stigmatization, psychosocial adaptation . Juvenilization - rhGH therapy, informed consent • Growth hormone treatment of short stature - Staturerelated stereotypes $\cdot$ OoL assumptions regarding short stature

\begin{abstract}
The unlimited availability of biosynthetic human growth hormone ( $\mathrm{rhGH}$ ) has contributed to the disassociation of the treatment of short stature from its causes. The rationale for treatment has traditionally rested upon the assumption that short stature, in the extreme, may constitute a physical disability, and otherwise represents a significant psychosocial burden for the individual. This review summarizes what is known about the psychosocial aspects of short stature and the quality of life benefits of rhGH treatment. Stereotypes and assumptions about short stature are evaluated in light of empirical findings. Problems of psychosocial adjustment are relatively common in the general population. Because of the salience of short stature, and its potential to serve as a lightning rod to divert attention from other factors interfering with a healthy psychological adaptation, the clinician must be watchful of misattributions for ongoing problems, or unrealistic predictions of the benefits of taller stature. For
\end{abstract}

these reasons, the clinician should consider incorporating a psychosocial component in the diagnostic evaluation to broaden potential treatment recommendations. Finally, studies of factors influencing family decisions regarding factors for and against rhGH therapy provide important clues to how clinicians might enhance the informed consent process.

Copyright $\odot 2005$ S. Karger AG, Basel

\section{Growth Hormone Treatment of Short Stature: Status of the Quality of Life Rationale}

The introduction of biosynthetic human growth hormone (rhGH) has made it possible to optimize the adult height of GH-deficient youths. This same technological advance created opportunities to provide treatment to those who are unusually short but test GH-sufficient. Conditions for which rhGH is efficacious in promoting faster growth and taller stature include a diverse set of conditions: Turner syndrome [1], chronic renal insufficiency [2], Prader-Willi syndrome [3], children born small for gestational age [4] and, most recently, idiopathic short stature (i.e., short, but without diagnosable pathology) [5].

With the possible exceptions of classic GH deficiency (GHD) and Prader-Willi syndrome, to which metabolic

\section{KARGER}

Fax +4161306 1234 E-Mail karger@karger.ch www.karger.com
(C) 2005 S. Karger AG, Basel 0301-0163/05/0636-0275\$22.00/0

Accessible online at:

www.karger.com/hre
David E. Sandberg, PhD

Pediatric Psychiatry and Psychology

The Women and Children's Hospital of Buffalo

219 Bryant Street, Buffalo, NY 14222 (USA)

Tel. +1 716878 7645, Fax +1 716888 3935, E-Mail dsandber@buffalo.edu 
benefits of rhGH have been ascribed, a primary goal of therapy for children and adolescents with short stature, regardless of etiology, is taller stature. Treatment of short children and adolescents is predicated on the beliefs that short stature is an undesirable physical characteristic associated with problems of adaptation and a diminished quality of life (QoL), and that hormonally-induced increases in height will improve QoL.

Allen and Fost [6] recently noted that the abundance of $\mathrm{rhGH}$, and uncertainty regarding the diagnosis of GHD, contribute to controversy regarding who should receive treatment. They infer from the growing number of conditions for which rhGH is prescribed that 'the cause of short stature is not morally relevant in deciding who is entitled to treatment' [6, p. 648]. These authors proposed that rhGH therapy is indicated when a disability in adaptation attributable to short stature is identified (rather than by virtue of a medical diagnosis), and that treatment should be aimed at correcting this disability through treatment up to the point that an adult height within the 'normal range' is attained, i.e., -5 th percentile.

To ascertain the degree to which the perspective delineated by Allen and Fost (i.e., height is a 'surrogate measure' of psychosocial adjustment) is reflected in the clinical research literature, we first conducted a MEDLINE ${ }^{\circledR}$ search (Ovid MEDLINE ${ }^{\circledR}<1966$ to February, Week 1, $2005>$ database) of this journal. A total of 3,214 articles were published in Hormone Research and its predecessor Hormones, during this period. A search using the keywords 'short', 'stature', or 'height' combined with 'growth hormone' generated 366 citations; 165 of these articles focused on the growth-promoting aspect of rhGH therapy. In contrast, the keywords 'short', 'stature', or 'height' combined with 'quality of life', 'psychological', 'psychosocial', 'self', or 'adjustment', generated only 43 citations; 19 of these were concerned primarily with the psychological aspects of short stature. Comparable imbalances between the auxologic and QoL benefits of $\mathrm{rhGH}$ are found if the literature search is expanded to include all MEDLINE $^{\circledR}$-indexed journals.

In light of the controversy surrounding the expanded use of rhGH, in particular the recent approval by the US Food and Drug Administration of rhGH for treatment of 'idiopathic short stature' [7], the objective of this review is to summarize what is known about the psychosocial aspects of short stature and the QoL benefits of rhGH therapy. Stereotypes and assumptions about short stature (and its treatment with $\mathrm{rhGH}$ ) will be evaluated in light of empirical findings. Because of space limitations, this review is selective. The investigations cited should only
Table 1. Empirical status of stature-related stereotypes

\begin{tabular}{|c|c|}
\hline Stereotype & Evidence \\
\hline $\begin{array}{l}\text { Children and adults with } \\
\text { short stature are less } \\
\text { psychosocially well } \\
\text { adjusted }\end{array}$ & $\begin{array}{l}\text { Generally supported by analogue } \\
\text { (laboratory-based) research }[8-11] \\
\text { Not supported by general } \\
\text { population- or clinic-based studies } \\
{[28,32,33]}\end{array}$ \\
\hline $\begin{array}{l}\text { Children and adults with } \\
\text { short stature are treated } \\
\text { poorly due to their } \\
\text { stature }\end{array}$ & $\begin{array}{l}\text { Mixed results from analogue studies } \\
{[16-18]} \\
\text { Evidence of teasing and juvenili- } \\
\text { zation from clinic-based studies } \\
{[27,28]}\end{array}$ \\
\hline $\begin{array}{l}\text { Short men are less } \\
\text { attractive and desirable } \\
\text { to women as dates or } \\
\text { husbands }\end{array}$ & $\begin{array}{l}\text { Generally supported by analogue } \\
\text { research }[10,19,20] \\
\text { Limited support in population-based } \\
\text { studies: effect attenuated when } \\
\text { statistically controlling for } \\
\text { confounding variables }[45,49]\end{array}$ \\
\hline $\begin{array}{l}\text { Children and adults with } \\
\text { short stature do less well } \\
\text { at school/are less } \\
\text { intelligent }\end{array}$ & $\begin{array}{l}\text { Generally supported by analogue } \\
\text { studies }[16,23] \\
\text { Not supported by general popula- } \\
\text { tion- or clinic-based studies of } \\
\text { children }[38-40] \text { or adults }[44,53]\end{array}$ \\
\hline $\begin{array}{l}\text { Adults with short stature } \\
\text { hold lower status } \\
\text { occupations and are paid } \\
\text { less }\end{array}$ & $\begin{array}{l}\text { Supported by analogue studies } \\
{[10,24,25]} \\
\text { Limited support in population-based } \\
\text { studies: effect attenuated when } \\
\text { statistically controlling for } \\
\text { confounding variables [ } 44-48]\end{array}$ \\
\hline
\end{tabular}

be considered as examples. Studies were identified on MEDLINE $^{\circledR}$ and PsychINFO ${ }^{\circledR}$ using the terms 'stature' or 'height' combined with 'quality of life' or 'psychological', 'psychosocial', 'self', or 'adjustment'. Priority was given to studies with stronger research designs.

\section{Stature-Related Stereotypes}

Stereotyping refers to a process in which identical characteristics are assigned to all individuals within a group, regardless of the actual variation among group members. Negative stereotypes regarding experiences and characteristics of individuals with short stature are plentiful and exemplars in the research literature can be classified as follows: accompanying psychological characteristics; differential treatment by others; social relationships, and education/occupation (table 1). 
Table 2. Analogue versus clinical/epidemiological research

\begin{tabular}{lll}
\hline Study category & Definition & Example \\
\hline Analogue research & $\begin{array}{l}\text { Used to create a situation simulating } \\
\text { real life } \\
\text { Facilitates the study of phenomena } \\
\text { under controlled conditions } \\
\text { Often includes experimental } \\
\text { manipulation of variables } \\
\text { Criticized as being of questionable } \\
\text { relevance to complicated social } \\
\text { phenomena [62] }\end{array}$ & $\begin{array}{l}\text { College students asked to estimate the } \\
\text { height of a male visitor introduced as } \\
\text { having one of five different academic } \\
\text { ranks. Mean height estimates for the } \\
\text { visitor increased with academic rank } \\
\text { [24] }\end{array}$ \\
\hline $\begin{array}{ll}\text { Examines condition of interest under } \\
\text { real-world circumstances }\end{array}$ & $\begin{array}{l}\text { Clinic-based studies of the psychosocial } \\
\text { adaptation of youths with short stature } \\
\text { [3] }\end{array}$ \\
& $\begin{array}{l}\text { [33] } \\
\text { Studies of peer acceptance and } \\
\text { reputation as a function of height [43] }\end{array}$ \\
\hline
\end{tabular}

Research on stereotypical beliefs about those with short stature is often conducted by assessing participants' perceptions in 'analogue' studies. Analogue studies are employed in psychological research to answer well-defined research questions by isolating aspects of everyday life and assessing them within a controlled setting (for example, the laboratory where volunteer college students participate as subjects). The validity of findings stemming from such research designs has been questioned when used to investigate complicated social phenomena. Analogue studies of the psychosocial concomitants of short stature that constrain information about the individual, or which place emphasis on stature, may unwittingly tap the stereotypes held by participants, but may be poor predictors of how participants perceive or treat an individual in the 'real world' (table 2).

Children's and adults' beliefs about height reliably demonstrate a bias toward the notion that 'taller is better' With few exceptions, both children and adults attribute significantly less favorable characteristics to short individuals compared to those of tall or average height [8-11]. It is thus not surprising that youths and adults of both genders prefer to be taller [12-14].

Some argue that individuals with short stature experience disadvantages in the way they are treated due to stature-related societal perceptions [15]. Mothers of preschool children differentially assign a less severe punishment for behavioral transgressions to short girls compared with tall and average counterparts [16]. 'Personal space' (i.e., the area around a person's body into which others may not intrude without arousing discomfort) has been used as a proxy of respect. Two studies investigated the relationship between a person's height and how much personal space they are given. Results were mixed: in one, the taller individual was given more space [17]; in the other, no differences in measured physical proximity afforded to the short vs. tall individual were found [18].

Research on the effects of height on social relationships focuses on heterosexual dating and partner selection. For dating relationships, findings support the conventional notion that taller is better, and this appears particularly true for males [10,19-21], but less so for females $[10,21]$. Regarding the importance of height in partner selection, the man's height is more important a consideration for women than the reverse [11,22].

When asked to evaluate classmates' competence, preschool boys rated small boys as better at 'Art' than tall boys; girls rated tall boys as smarter than small boys; but girls' height did not correlate with ratings [16]. Mothers rated tall boys and girls as more competent than small boys in the majority of domains [16], and had greater expectations for mastery and achievement from taller children [23].

With regard to adults' occupational status, research results show undergraduates judge individuals who have more prestigious occupations as taller than those of less prestige $[24,25]$. They also expect taller people to have a higher professional status than shorter people [10]. 
QoL Assumptions regarding Short Stature and Supporting Evidence (table 3)

\section{Assumption 1: Patients with Short Stature Experience} Chronic Psychosocial Stress

Early studies of the psychosocial aspects of short stature showed it was associated with teasing and juvenilization (i.e., treating individuals as if they were younger due to a misperception of chronologic age). Participation in these studies was generally restricted to patients with complex medical conditions and little attention was directed toward bias introduced by subject selection factors [26]. To assume these findings are generalizable to the larger population of children with short stature currently seen by endocrinologists, especially those classified as having idiopathic short stature (ISS), is questionable.

Two relatively recent studies, both using standardized measures on patients consecutively referred to endocrine clinics for an evaluation of growth, found that the majority of children, approximately $60-70 \%$, experienced teasing or juvenilization $[27,28]$. Intuitively, one might expect the incidence of these negative experiences to be negatively correlated with the child's relative height (i.e., negative experiences would decline as height increased); however, this was not the case: relative height (range -3.1 to -0.2 height $\mathrm{SD}$ ) was not related to children's or parents' reports of stature-related psychosocial stressors [28]. Interpretations of findings from this latter study must be qualified by the fact that a portion of the sample would not be considered 'short'.

Results of these clinical studies corroborate anecdotal reports that short stature elicits predictable social responses during childhood and adolescence, and conform to stereotypes that individuals with short stature are perceived and treated negatively. Missing from these clinicbased reports is an assessment of the degree to which teasing or juvenilization are associated with psychological dysfunction.

\section{Assumption 2: Patients with Short Stature Exhibit Clinically Significant Problems of Psychosocial Adaptation}

A commonly held assumption is that patients with short stature exhibit higher rates of clinically significant behavioral or emotional problems [29]. Implicit in this belief is the expectation that the prevalence of psychiatric problems is significantly higher among patients with short stature than it is for the general population (estimated from epidemiological studies to be approximately $12 \%$ ) $[30,31]$. However, this does not appear to be the case
Table 3. Assumptions underlying rhGH therapy

\begin{tabular}{ll}
\hline Assumption & Evidence \\
\hline $\begin{array}{l}\text { Patients with short stature } \\
\text { experience chronic psychosocial } \\
\text { stress }\end{array}$ & $\begin{array}{l}\text { Supported by clinic-based } \\
\text { studies [27, 28] }\end{array}$ \\
\hline $\begin{array}{l}\text { Patients with short stature } \\
\text { exhibit clinically significant } \\
\text { problems of psychosocial }\end{array}$ & $\begin{array}{l}\text { Not generally supported } \\
\text { [28, 32-34, 54] }\end{array}$ \\
$\begin{array}{l}\text { adaptation } \\
\begin{array}{l}\text { Short youths and adults in the } \\
\text { aeneral population are similarly }\end{array}\end{array}$ & $\begin{array}{l}\text { Not supported in children, } \\
\text { adolescents [39, 41-43] or } \\
\text { adjustm problems of social }\end{array}$ \\
$\begin{array}{l}\text { Stature-related social stress } \\
\text { results in significant problems } \\
\text { of psychosocial adjustment }\end{array}$ & $\begin{array}{l}\text { Limited support: though } \\
\text { teasing and juvenilization } \\
\text { were related to behavior }\end{array}$ \\
& $\begin{array}{l}\text { problems [27], overall psycho- } \\
\text { social adaptation was } \\
\text { equivalent to community }\end{array}$ \\
norms [33]
\end{tabular}

Increases in growth velocity and height induced by rhGH therapy result in an improved QoL Not supported [14, 32, 53, 54]

when selection biases in participant recruitment are minimized. For example, self-reported self-esteem scale scores for short youths referred for evaluation of short stature were higher (i.e., more positive) than questionnaire norms despite reports that the majority of these individuals experienced teasing and juvenilization [28]. The same was true for behavior disturbances: patients reported significantly fewer problems than questionnaire norms, and parental reports indicated that patients were indistinguishable from the norms in terms of behavioral and emotional functioning [28]. Similar findings were reported in other clinic-based studies [32, 33]. Interestingly, relatively taller children received higher problem scores (i.e., indicating more problems) [33]. In contrast, industry-sponsored studies typically report significantly more behavioral and emotional problems among children with short stature relative to norms as measured by both selfand parental report [34, 35]. Unfortunately, key details essential to gauge the representativeness of the samples were not provided, e.g., the total number of eligible patients and the method of targeting participants for behavioral studies. These and other methodological concerns are discussed more fully elsewhere [36]. Studies that featured clinically representative samples have shown be- 
havioral adjustment to be comparable to populationbased norms [28, 33] and classmates [37].

\section{Corollary of Assumptions 1 and 2: Individuals with}

Short Stature in the General Population Also Exhibit

\section{Significant Problems of Psychosocial Adaptation}

Children and Adolescents. Although rarely articulated, it follows from both preceding assumptions that short youths who are not referred for a medical evaluation are similarly at risk for psychosocial adaptation problems. In the prospective, longitudinal Wessex Growth Study, in which the sample is comprised of short but otherwise healthy children from the general population, no evidence of serious psychosocial or academic disadvantage was found [38-41]. Although individuals in the short stature group preferred to be taller, and reported more bullying than their taller peers [12], neither the desire for physical change nor bullying had measurable effects on school performance or self-esteem [38, 39, 41], suggesting that stigmatized individuals use self-protective cognitive mechanisms that allow self-esteem to remain intact [33].

In the largest study of its type, and the only one conducted on a national probability sample of the US population, Wilson et al. [42] assessed the relationship between stature and two measures of intellectual function: IQ and academic achievement. Statistically controlling for potentially confounding background characteristics, subject's height contributed significantly (approximately $2 \%$ ) to the prediction of both indices. The Wessex Growth Study replicated this general finding. However, as in the US study, height explained only $2 \%$ of the variance in IQ. Socioeconomic factors, rather than stature, best predicted psychosocial and academic outcomes [39]. A difficulty in interpreting this literature is that short stature might contribute to lower socioeconomic status (SES) in the family of origin, and that by statistically controlling for SES, the influence of short stature is obscured. In other words, the possibility exists that short stature contributes to downward socioeconomic mobility, perhaps due to social or psychological burdens associated with the physical trait. It also may be that a low SES, in which one lacks certain resources (e.g., good prenatal care, adequate healthcare or nutrition), may contribute to short stature.

In a recent study using a novel research design, the influence of height on students' $(n=956$; grades 6-12; approximately 11-18 years old) psychosocial adaptation was assessed using peer informants [43]. Statistically significant relationships were not detected between height and measures of friendship, popularity, or most aspects of reputation among peers, despite substantial statistical power. Findings did not vary by participant gender, peer or self-report, or whether data from the entire sample were used or subgroups of very short $(\leq-2.25$ height SD; 1 st percentile) or very tall students ( $\geq+2.25$ height SD; 99th percentile) students were contrasted with comparison classmates of average height (25th to 75 th percentile for norms). In the lower grades, shorter students were perceived by peers to be younger than their age. However, this perception was not meaningfully related to measures of social acceptance or other aspects of reputation among peers. The authors concluded that extremes of stature in the general population - either short or tall have minimal detectable influence on peer perceptions of social behavior, friendship, or acceptance [43]. Notably, this study did not assess dating or romantic relations.

Adults. A statistically significant relationship between men's heights and the likelihood of completing college was not found [44]. Taller men were not more likely to achieve higher professional status when analyses controlled for educational attainment [44]. Studies of the relationship between height and income often report that tall men and women earn more than their shorter colleagues [44-48]. However, when relevant background information (i.e., potentially confounding variables such as age, health, education and family of origin characteristics) are controlled for statistically, the relationship between height and income is attenuated [44, 48].

The relationship between height and marriage rates varies by study. In the National Child Development Study, a longitudinal study of British citizens, the probability of being married was 7\% lower for short men ( $\leq 9$ th percentile) and 5\% lower for tall women ( $\geq 90$ th percentile) than for adults of average height (20th to 79th percentiles), when statistically controlling for social class, education, health, race, and region of residence [45]. Contrasting findings derive from the US National Longitudinal Survey of Youth, a study featuring a comparable research design. Although short men exhibited lower rates of first marriage than those of average height, this effect disappeared once family-of-origin variables (parental education, poverty status, and region of the country) were taken into account; no consistent relationship was found between women's height and marriage rates [49, 50].

Assumption 3: Height-Related Social Stress Results in Significant Problems of Psychological Adjustment

As both teasing [51, 52] and psychological adaptation problems [31] are relatively common among children and adolescents, support for Assumption 3 should come from 
a demonstrated statistical link between stressful staturerelated experiences and psychosocial dysfunction.

In the one study that specifically addressed this issue, parental report of stature-related teasing predicted increased emotional problems [27]. The proportion of unique variance in problem scores attributable to teasing was approximately $2 \%$ and increased (to between 4 and $5 \%$ ) when the frequency of teasing was taken into account. Juvenilization also contributed unique explanatory value, and summated with teasing as a negative influence on psychosocial adaptation.

To interpret the clinical significance of these effects, one must view them within the context of the mean level of behavior problems in this sample. As noted earlier (see Assumption 2), the psychological adaptation of short youths in this same clinic-referred cohort was comparable to community norms [33]. Thus, the possibility exists that stature-related stresses may contribute to variability in adaptation that falls within the 'normal range'. Of course, this interpretation does not imply that psychosocial stresses related to short stature should be ignored (see Recommendations for the Clinician, below).

Assumption 4: Increased Growth Velocity and Height Induced by rhGH Therapy Result in Improved QoL

Three randomized controlled trials of rhGH treatment in ISS (only one of which employed a placebo control group), were designed to investigate psychological outcomes. In the Wessex Growth Study, children who were treated with rhGH therapy were compared with those in an untreated control group at recruitment and after 3 and 5 years [53]. Despite a significant increase in height in the treatment group, there were no differences between the groups on the behavioral measures at any of the three assessments. Comparable results were found in a more recent study in which, despite increased height in the treated group, no improvement on self- or parental report measures of psychosocial adaptation and self-esteem were found [32].

In the sole randomized, double-blind, placebo-controlled study of the psychosocial effects of rhGH treatment in ISS, the psychosocial adaptation and self-esteem of youths in the treated and placebo groups were comparable to the general population prior to treatment initiation [54]. However, relatively taller children exhibited more emotional problems at baseline than shorter youths. This counter-intuitive finding replicates an observation from an independent clinic-based study [33]. Significant differences between the groups in psychosocial adaptation were not detected in the first 2 years of treatment. In year 4, however, parent-reported behavior problems for the placebo-treated group were significantly higher than the rhGH-treated group. Scores on the self-esteem measure did not differentiate the groups at any time point. Interpretation of the apparent benefit of rhGH on behavioral functioning (but not self-esteem) is complicated by the fact that no systematic relationship was observed between participant's attained height or the change in height, and annual changes in the measure of psychosocial adjustment.

Finally, in a retrospective study of young adults who either had or had not been treated with rhGH therapy for their ISS, no differences in education level or QoL were found [14], though the treated patients had a romantic partner less often than participants who did not receive rhGH therapy in childhood.

Although the focus of the 'to treat or not to treat' debate is directed at rhGH therapy, androgen treatment of boys with constitutional growth delay has long been turned to as a strategy to accelerate growth velocity, hasten the onset of secondary sex characteristics and, thereby, ameliorate perceived psychological distress without sacrificing adult height [55-57]. There has never been a head-to-head comparison of the psychological benefits of rhGH versus androgen therapy. A direct comparison is tantalizing considering the differences in the objective of treatment (i.e., hastening pubertal progression versus achievement of taller adult height), duration of treatment, and cost.

\section{Conclusions and Recommendations}

\section{Summary of Studies}

Commonly held beliefs and attitudes serve as implicit assumptions in the QoL rationale for applications of rhGH therapy beyond the traditional role of hormone replacement. In view of the findings on stereotypes, particularly research findings gleaned from laboratory studies, it is understandable that parents of children with short stature may be concerned about their child's psychosocial and educational adaptation. However, there is less support for these findings from clinic- or general population-based research on the real-world experiences of children and adults with short stature. Similarly, research regarding the assumptions on which the rationale for rhGH therapy are based, shows only partial support. 
Table 4. Recommendations for clinicians ${ }^{\mathrm{a}}$

\begin{tabular}{ll}
\hline Dos & Don'ts \\
\hline $\begin{array}{l}\text { Conduct a comprehensive } \\
\text { psychosocial assessment }\end{array}$ & $\begin{array}{l}\text { If problems of psychosocial } \\
\text { adaptation are detected, } \\
\text { do not assume that these are } \\
\text { attributable to short stature }\end{array}$ \\
\hline
\end{tabular}

Recommend psychosocial strategies to directly address predictable social challenges associated with short stature [63]

Discourage the expectation that taller stature is associated with changes in QoL [14, 32, 43, 53]

Be aware of and address factors the parent and patient use in making their decision $[60,61]$

Discuss treatment efficacy in terms of the degree of certainty and magnitude of effects [5]

Do not assume the parent or patient wants rhGH therapy

Do not minimize long-term side effects while emphasizing short-term safety

Do not minimize potential monetary costs associated with rhGH therapy ${ }^{\mathrm{b}}$; discuss these prior to initiating therapy

Do not give the parent or child unrealistic expectations about the growth-promoting benefits of rhGH will achieve Do not delay in evaluating girls with poor growth because of the belief that short stature is less a problem [64]

\footnotetext{
${ }^{\text {a }}$ Recommendations reflect the authors' opinions based on the cited literature and personal clinical experiences.

${ }^{\mathrm{b}}$ Of greater relevance in the USA.
}

\section{Recommendations for the Clinician (table 4)}

Practice guidelines for the use of rhGH therapy in children with short stature [58, p. 865] clearly state that decisions regarding 'instituting or continuing therapy should be individualized... and be guided by the goal of improving the quality of life [italics added] of the child and future adult'. These recommendations are echoed by Allen and Fost [6] who emphasize that access to rhGH therapy should be guided by the identification and amelioration of disability stemming from short stature.

Identifying youths who experience short stature as a 'disability' is a challenging task. The fact that the child or adolescent experiences teasing or juvenilization, or that the family is seeking a consultation with a pediatric endocrinologist regarding growth-promoting therapies, are insufficient to make this determination. Psychosocial stress is a common phenomenon in child development and, by itself, does not imply psychiatric dysfunction or even significant problems of psychosocial adaptation. Because of the salience of short stature and its potential to serve as a lightning rod to divert attention from other stressors, clinicians must be watchful of misattributions on the part of the child, parents, or others. This influence may direct attention away from prescribing psychosocial interventions for maladaptive coping [58]. Noeker and Haverkamp [59] developed a very useful conceptual framework to guide the psychological assessment of youths with short stature.

Finally, clinicians should be aware that parents may evaluate factors for and against rhGH therapy for their children very differently from physicians [60, 61]. Factors that parents consider (in order of descending importance) include risk of long-term side effects, out-of-pocket costs, the child's attitude toward wanting rhGH therapy, the likelihood of a height increase, the magnitude of the height increase, and the route of rhGH administration [60]. Given the importance of these factors to families, it would be prudent to gear interactions toward addressing these priorities. To this list, we would add the importance of making explicit the assumptions that the child and family (and physician) hold concerning the liabilities of short stature and the expected benefits of rhGH therapy.

\section{Acknowledgement}

We acknowledge the support of Children's Growth Foundation in sponsoring a unique integration of pediatric endocrine and psychoendocrine clinical services at The Women and Children's Hospital of Buffalo. 


\section{References}

-1 Saenger P, Wikland KA, Conway GS, Davenport M, Gravholt CH, Hintz R, et al: Recommendations for the diagnosis and management of Turner syndrome. J Clin Endocrinol Metab 2001;86:3061-3069.

-2 Vimalachandra D, Craig JC, Cowell CT, Knight JF: Growth hormone treatment in children with chronic renal failure: A meta-analysis of randomized controlled trials. J Pediatr 2001;139:560-567.

3 Cassidy SB: Prader-Willi syndrome in the new millennium. Endocrinologist 2001;10(suppl 1): $1 \mathrm{~S}-73 \mathrm{~S}$.

-4 Sas T, de Waal W, Mulder P, Houdijk M, Jansen M, Reeser M, et al: Growth hormone treatment in children with short stature born small for gestational age: 5-year results of a randomized, double-blind, dose-response trial. J Clin Endocrinol Metab 1999;84:3064-3070.

-5 Finkelstein BS, Imperiale TF, Speroff T, Marrero U, Radcliffe DJ, Cuttler L: Effect of growth hormone therapy on height in children with idiopathic short stature: A meta-analysis. Arch Pediatr Adolesc Med 2002;156:230-240.

-6 Allen DB, Fost N: hGH for short stature: Ethical issues raised by expanded access. J Pediatr 2004; 144:648-652.

7 US Food and Drug Administration: FDA approves Humatrope for short stature. FDA Talk Paper. July 25, 2003. Available at: www.fda. gov/bbs/topics/ANSWERS/2003/ANS01242. html. Accessed May 3, 2005.

8 Clopper R, Mazur T, Ellis AM, Michael P: Height and children's stereotypes; in Stabler B, Underwood LE (eds): Growth, Stature, and Adaptation. Chapel Hill, University of North Carolina at Chapel Hill, 1994, pp 7-18.

9 Martel LF, Biller H: Stature and Stigma: The Biopsychosocial Development of Short Males. Lexington, Lexington Books, 1987.

10 Jackson LA, Ervin KS: Height stereotypes of women and men: The liabilities of shortness for both sexes. J Soc Psychol 1992;132:433445 .

11 Gacsaly SA, Borges CA: The male physique and behavioral expectancies. J Psychol 1979; 101:97-102.

12 Voss LD, Mulligan J: Bullying in school: Are short pupils at risk? Questionnaire study in a cohort. BMJ 2000;320:612-613.

13 Arkoff A, Weaver HB: Body image and body dissatisfaction in Japanese-Americans. J Soc Psychol1966;68:323-330.

14 Rekers-Mombarg LT, Busschbach JJ, Massa GG, Dicke J, Wit JM: Quality of life of young adults with idiopathic short stature: Effect of growth hormone treatment. Acta Paediatr 1998;87:865-870.

15 Underwood LE: The social cost of being short: Societal perceptions and biases. Acta Paediatr Suppl 1991;377:3-8.

16 Eisenberg N, Roth K, Bryniarski KA, Murray $\mathrm{E}$ : Sex differences in the relationship of height to children's actual and attributed social and cognitive competencies. Sex Roles 1984;11: 719-734.
17 Hartnett JJ, Bailey KG, Hartley CS: Body height, position, and sex as determinants of personal space. J Psychol 1974;87:129-136.

18 Bailey KG, Caffrey JV, Hartnett JJ: Body size as implied threat: Effects on personal space and person perception. Percept Mot Skills 1976;43: 223-230.

19 Beigel HG: Body height in mate selection. J Soc Psychol 1954;39:257-268.

20 Graziano W, Brothen T, Berscheid E: Height and attraction: Do men and women see eye-toeye? J Pers 1978;46:128-145.

-21 Hensley WE: Height as a basis for interpersonal attraction. Adolescence 1994;29:469-474.

22 Pierce CA: Body height and romantic attraction: A meta-analytic test of the male-taller norm. Soc Behav Pers 1996;24:143-150.

23 Brackbill Y, Nevill DD: Parental expectations of achievement as affected by children's height. Merrill-Palmer Q 1981;27:429-441.

24 Wilson PR: Perceptual distortion of height as a function of ascribed academic status. J Soc Psychol 1968;74:97-102.

25 Lechelt EC: Occupational affiliation and ratings of physical height and personal esteem. Psychol Rep 1975;36:943-946.

26 Sandberg DE: Short stature: Intellectual and behavioral aspects; in Lifshitz F (ed): Pediatric Endocrinology, ed 3. New York, Dekker, 1996, pp 149-162.

27 Sandberg DE, Michael P: Psychosocial stresses related to short stature: Does their presence imply psychiatric dysfunction? In Drotar D (ed): Assessing Pediatric Health-Related Quality of Life and Functional Status: Implications for Research. Mahwah, Lawrence Erlbaum Assoc, 1998, pp 287-312.

28 Zimet GD, Cutler M, Litvene M, Dahms W, Owens R, Cuttler L: Psychological adjustment of children evaluated for short stature: a preliminary report. J Dev Behav Pediatr 1995;16: 264-270.

29 Meyer-Bahlburg HFL: Short stature: Psychological issues; in Lifshitz F (ed): Pediatric Endocrinology. New York, Dekker, 1990, pp 173-196.

30 Gould MS, Wunsch-Hitzig R, Dohrenwend B: Estimating the prevalence of childhood psychopathology. A critical review. J Am Acad Child Psychiatry 1981;20:462-476.

31 Shaffer D, Fisher P, Dulcan MK, Davies M, Piacentini J, Schwab-Stone ME, et al: The NIMH Diagnostic Interview Schedule for Children Version 2.3 (DISC-2.3): Description, acceptability, prevalence rates, and performance in the MECA Study. Methods for the Epidemiology of Child and Adolescent Mental Disorders Study. J Am Acad Child Adolesc Psychiatry 1996;35:865-877.

32 Theunissen NC, Kamp GA, Koopman HM, Zwinderman KA, Vogels T, Wit JM: Quality of life and self-esteem in children treated for idiopathic short stature. J Pediatr 2002;140: 507-515.
33 Sandberg DE, Brook AE, Campos SP: Short stature: a psychosocial burden requiring growth hormone therapy? Pediatrics 1994;94:832840.

34 Stabler B, Clopper RR, Siegel PT, Stoppani C, Compton PG, Underwood LE: Academic achievement and psychological adjustment in short children. The National Cooperative Growth Study. J Dev Behav Pediatr 1994; 15: $1-6$.

-35 Steinhausen HC, Dorr HG, Kannenberg R, Malin Z: The behavior profile of children and adolescents with short stature. J Dev Behav Pediatr 2000;21:423-428.

-36 Sandberg DE, Kranzler J, Bukowski WM, Rosenbloom AL: Psychosocial aspects of short stature and growth hormone therapy. J Pediatr 1999:135:133-134.

-37 Gilmour J, Skuse D: Short stature - the role of intelligence in psychosocial adjustment. Arch Dis Child 1996; 75:25-31.

38 Voss LD, Mulligan J: The short 'normal' child in school: Self-esteem, behavior and attainment before puberty (The Wessex Growth Study); in Stabler B, Underwood LE (eds): Growth, Stature and Adaptation. Chapel Hill, University of North Carolina at Chapel Hill Press, 1994, pp 47-64.

- 39 Downie AB, Mulligan J, Stratford RJ, Betts PR, Voss LD: Are short normal children at a disadvantage? The Wessex Growth Study. BMJ 1997;314:97-100.

40 Voss LD: Short but normal. Arch Dis Child 1999;81:370-371.

41 Ulph F, Betts P, Mulligan J, Stratford RJ: Personality functioning: the influence of stature. Arch Dis Child 2004;89:17-21.

42 Wilson DM, Hammer LD, Duncan PM, Dornbusch SM, Ritter PL, Hintz RL, et al: Growth and intellectual development. Pediatrics 1986; 78:646-650.

43 Sandberg DE, Bukowski WM, Fung CM, Noll RB: Height and social adjustment: Are extremes a cause for concern and action? Pediatrics 2004:114:744-750.

-44 Ekwo E, Gosselink C, Roizen N, Brazdziunas D: The effect of height on family income. Am J Hum Biol 1991;3:181-188.

45 Harper B: Beauty, stature and the labour market: A British cohort study. Oxford Bull Econ Statist 2000;62:771-800.

46 Sargent JD, Blanchflower DG: Obesity and stature in adolescence and earnings in young adulthood. Analysis of a British birth cohort. Arch Pediatr Adolesc Med 1994;148:681687.

47 Persico N, Postlewaite RJ, Silverman D: The effect of adolescent experience on labor market outcomes: The case of height. J Polit Econ 2004;112:1019-1053.

48 Judge TA, Cable DM: The effect of physical height on workplace success and income: Preliminary test of a theoretical model. J Appl Psychol 2004;89:428-441. 
-49 Fu H, Goldman N: Incorporating health into models of marriage choice: Demographic and sociological perspectives. J Marriage Fam 1996;58:740-758.

-50 Fu H, Goldman N: The association between health-related behaviours and the risk of divorce in the USA. J Biosoc Sci 2000;32:6388.

-51 Keltner D, Capps L, Kring AM, Young RC, Heerey EA: Just teasing: A conceptual analysis and empirical review. Psychol Bull 2001;127: 229-248.

-52 Warm TR: The role of teasing in development and vice versa. J Dev Behav Pediatr 1997;18: 97-101.

53 Downie AB, Mulligan J, McCaughey ES, Stratford RJ, Betts PR, Voss LD: Psychological response to growth hormone treatment in short normal children. Arch Dis Child 1996;75:3235.

54 Ross JL, Sandberg DE, Rose SR, Leschek EW, Baron J, Chipman JJ, et al: Psychological adaptation in children with idiopathic short stature treated with growth hormone or placebo. J Clin Endocrinol Metab 2004;89:4873-4878.
55 Wilson DM, McCauley E, Brown DR, Dudley $\mathrm{R}$ : Oxandrolone therapy in constitutionally delayed growth and puberty. Bio-Technology General Corporation Cooperative Study Group. Pediatrics 1995;96:1095-1100.

56 Strickland AL: Long-term results of treatment with low-dose fluoxymesterone in constitutional delay of growth and puberty and in genetic short stature. Pediatrics 1993;91:716720.

57 Richman RA, Kirsch LR: Testosterone treatment in adolescent boys with constitutional delay in growth and development. N Engl J Med 1988;319:1563-1567.

58 Anonymous: Guidelines for the use of growth hormone in children with short stature. A report by the Drug and Therapeutics Committee of the Lawson Wilkins Pediatric Endocrine Society. J Pediatr 1995;127:857-867.
59 Noeker M, Haverkamp F: Adjustment in conditions with short stature: A conceptual framework. J Pediatr Endocrinol Metab 2000;13: 1585-1594.

60 Finkelstein BS, Singh J, Silvers JB, Marrero U, Neuhauser D, Cuttler L: Patient attitudes and preferences regarding treatment: GH therapy for childhood short stature. Horm Res 1999; 51(suppl 1):67-72.

61 Singh J, Cuttler L, Shin M, Silvers JB, Neuhauser D: Medical decision-making and the patient: understanding preference patterns for growth hormone therapy using conjoint analysis. Medical Care 1998;36(suppl 8):AS31AS45.

62 Kazdin AE: Research Design in Clinical Psychology, ed 4. Boston, Allyn \& Bacon, 2003.

63 Eminson DM, Powell RP, Hollis S: Cognitive behavioral interventions with short statured boys: a pilot study; in Stabler B, Underwood LE (eds): Growth, Stature, and Adaptation. Chapel Hill, The University of North Carolina at Chapel Hill, 1994, pp 135-150.

-64 Grimberg A, Kutikov JK, Cucchiara AJ: Sex differences in patients referred for evaluation of poor growth. J Pediatr 2005;146:212-216. 